\title{
Comparative study of optimised BCR sequential extraction scheme and acid leaching of elements in the certified reference material NIST 2711
}

\author{
Bronwyn L. Larner ${ }^{\mathrm{a}, *}$, Andrew J. Seen ${ }^{\mathrm{a}}$, Ashley T. Townsend ${ }^{\mathrm{b}}$ \\ a School of Chemistry, University of Tasmania, Locked Bag 1371, Launceston, Tasmania 7250, Australia \\ ${ }^{\mathrm{b}}$ Central Science Laboratory, University of Tasmania, Private Bag 74, Hobart, Tasmania 7001, Australia
}

Received 29 June 2005; received in revised form 21 September 2005; accepted 26 September 2005

Available online 27 October 2005

\begin{abstract}
The optimised BCR sequential extraction procedure and a $4 \mathrm{~h} 1 \mathrm{~mol} \mathrm{~L}^{-1} \mathrm{HCl}$ partial extraction have been performed on the NIST 2711 reference material for a suite of 12 elements (Cd, $\mathrm{Sb}, \mathrm{Pb}, \mathrm{Al}, \mathrm{Cr}, \mathrm{Mn}, \mathrm{Fe}, \mathrm{Co}, \mathrm{Ni}, \mathrm{Cu}, \mathrm{Zn}, \mathrm{As})$ using magnetic sector ICP-MS. A pseudo-total aqua regia digest of NIST 2711 has also been undertaken for quality assurance purposes, and comparison of the sum of the four BCR fractions, which included an aqua regia digest on the residue, with the pseudo-total aqua regia digest has been used to assess the accuracy of the BCR partitioning approach. As a result of this work, discrepancies between previous studies about BCR partitioning of elements in NIST 2711 have been discussed and an increase in confidence about the use of BCR partitioning scheme on seven elements $(\mathrm{Cd}, \mathrm{Pb}, \mathrm{Al}, \mathrm{Mn}, \mathrm{Fe}, \mathrm{Cu}, \mathrm{Zn})$ in this standard material has been obtained. On the other hand, BCR partitioning for $\mathrm{Sb}, \mathrm{Cr}, \mathrm{Co}, \mathrm{Ni}$ and As has been provided for the first time. Partial extraction results are also reported for the same 12 elements analysed by the optimised BCR procedure, with the partial extraction results exhibiting a strong correlation with the sum of the three labile steps of the BCR procedure.
\end{abstract}

(C) 2005 Elsevier B.V. All rights reserved.

Keywords: NIST 2711; Sequential extraction; BCR sequential extraction; Partial extraction; ICP-MS

\section{Introduction}

The shift away from simply measuring total contaminant levels in sediments to a risk-based approach to determine sediment quality (as is the case for the Australian and New Zealand Environment and Conservation Council, ANZECC, Water Quality Guidelines, 2000) has stimulated the need for alternative methods of assessing sediment quality [1]. Under the ANZECC risk-based approach, if a total metal analysis on a sediment sample exceeds the sediment guideline value, further testing would be undertaken to determine the factors controlling bioavailability of the contaminant metal. For example, sulfide and organic content of the sediment, and contaminant speciation within the sediment, are critical in controlling whether or not contaminants will be readily available within the sediment porewater. Partial (single) and sequential extraction procedures are two techniques

\footnotetext{
* Corresponding author. Tel.: +61 363243869 .

E-mail address: blarner@utas.edu.au (B.L. Larner).
}

that have been used for determining the extractable forms of metals within sediments [2].

Partial extractions unselectively target labile metals with the degree of extraction dependent upon the severity of the reagent [3]. In contrast, sequential extraction procedures have been applied to soils and sediments to characterise their respective metal fractions, by selectively targeting and releasing metals bound in certain geochemical phases, such as carbonate, iron and manganese oxide/hydroxide, sulfidic, organic, and silicate [4].

Several problems have been identified with the use of sequential extraction procedures, including non-selectivity and readsorption [5-8]. Consequently, fractionation of metals is operationally defined in terms of the extraction mechanism used to release the metals rather than in terms of the discrete geochemical phases. One of the more commonly used sequential extraction procedures is the BCR (Community Bureau of Reference of the European Commission, now the Standards, Measuring and Testing Programme) procedure [9]. The BCR procedure aims to fractionate metals into the operationally defined phases of acid 
extractable, reducible, oxidisable and residual, with the steps targeting exchangeable and carbonate bound metals, iron and manganese oxide/hydroxide associated metals, metals bound to sulfide and organic phases, and mineral phases, respectively. Due to the many schemes and variations in use, the BCR procedure was originally developed to try to standardise sequential extraction schemes. The original procedure has since been modified [10], including changes to the concentration of the reagent and $\mathrm{pH}$ of the second step, which has resulted in better precision between laboratories for the extraction of reducible metals. The addition of a fourth step, an aqua regia digest on the solid residue remaining after Step 3, has provided the opportunity for quality assurance by comparison of the sum of the four BCR steps to an independent aqua regia analysis on a second portion of sample [10].

In contrast to sequential extraction schemes, partial extractions are a simple and cost effective way to investigate the labile metals in sediments. Although there are numerous methods for partial extractions, they generally fall into three groups: (i) dilute solutions of strong mineral acids, (ii) weak acids and (iii) solutions of complexing or reducing agents $[11,12]$.

Dilute $\mathrm{HCl}$ is one of the more common partial extractants used [3,12-14]. It extracts labile metals, but has little effect on breaking up the silicate lattice and residual phase metals [3], hence leaving metals bound to these phases untouched. Partial extractions have also been shown to correlate better with trace metal levels in benthic organisms than total digests [15-17].

The application of partial (single) and sequential extractions as a means of assessing sediment quality has also resulted in the development and certification of new reference materials, such as BCR 483 and BCR 484 (sewage sludge amended soils certified for EDTA and acetic acid extractions) [18], and BCR 701 (lake sediment certified for BCR 3-step sequential extraction) $[19,20]$. A number of other reference materials, including NIST 2711 (soil certified for total metals and non-certified EPA Method 3050 leachable concentrations), have been used for assessing sequential extraction procedures. NIST 2711 is a moderately contaminated soil intended for quality assurance of analysis of soils and sediments, and although no certified values exist for sequential extractions performed upon NIST 2711, a variety of sequential extraction procedures have been applied to this reference material [21-25].

This paper investigates the partitioning and accuracy of 12 elements (Cd, Sb, Pb, Al, Cr, Mn, Fe, Co, Ni, Cu, $\mathrm{Zn}$ and $\mathrm{As}$ ) in NIST 2711 using the optimised BCR sequential extraction procedure [10] and a dilute acid single step partial extraction with multi-element analysis by magnetic sector ICP-MS. Multielement determination by ICP-MS has not been previously used for partitioning of elements in NIST 2711 using the optimised BCR procedure.

Whilst results have previously been reported for $\mathrm{Pb}, \mathrm{Al}, \mathrm{Mn}$, $\mathrm{Fe}, \mathrm{Cu}$ and $\mathrm{Zn}$ using the optimised BCR procedure [24,25], discrepancies existed between those studies for $\mathrm{Pb}, \mathrm{Al}$ and Mn. This work clarifies those discrepancies, and provides partitioning results for $\mathrm{Cd}, \mathrm{Sb}, \mathrm{Cr}, \mathrm{Co}, \mathrm{Ni}$ and $\mathrm{As}$ under the optimised BCR procedure. Pseudo-total (aqua regia) metal analyses are also reported for NIST 2711 and have been compared with the sum of the four BCR steps for quality assurance purposes. Partial extraction $\left(4 \mathrm{~h} 1 \mathrm{~mol} \mathrm{~L}^{-1} \mathrm{HCl}\right)$ results are also reported for the 12 elements analysed, and a comparison of the partial extraction results has been made with the non-residual, labile metals released using the BCR procedure. The metals partitioning data reported here for NIST 2711 will be valuable for further environmental studies and for inter-laboratory comparisons.

\section{Experimental}

\subsection{Standard reference material NIST 2711}

NIST 2711 is a moderately contaminated Montana soil produced by National Institute of Standards and Technology (NIST) [26]. The original sample was collected from the till layer of a wheat field, where it was subsequently air dried, sieved to $2 \mathrm{~mm}$ and ground to pass through a $74 \mu \mathrm{m}$ screen [26]. Three $1 \mathrm{~g}$ samples were dried at $105^{\circ} \mathrm{C}$ for $24 \mathrm{~h}$ to calculate moisture content. This enabled concentrations to be reported on a $\mu \mathrm{g} \mathrm{g}^{-1}$ dry weight basis.

\subsection{BCR sequential extraction procedure}

The optimised BCR procedure was followed according to the procedure described fully in Rauret et al. [10]. A brief summary of the method is shown in Table 1. Each extraction step was performed in triplicate, starting with $1 \mathrm{~g}$ of original material. All reagents were of analytical grade quality or better, with all solutions and dilutions prepared in Milli-Q water (resistance $=18.2 \mathrm{M} \Omega \mathrm{cm}^{-1}$ ) . The aqua regia residual step performed on the residue from Step 3 was based on Australian Standard AS 4479.2, rather than the recommended ISO 11466 method,

Table 1

Reagents and conditions employed for the modified BCR sequential extraction procedure

\begin{tabular}{|c|c|c|}
\hline Step & Fraction & Reagent and conditions \\
\hline 1 & Acid extractable & $1 \mathrm{~g}$ NIST $2711,40 \mathrm{~mL} 0.11 \mathrm{~mol} \mathrm{~L}^{-1} \mathrm{CH}_{3} \mathrm{COOH}$, shaken $16 \mathrm{~h}$ at room temperature, centrifuged $3000 \times g$ for $20 \mathrm{~min}$ \\
\hline 2 & Reducible & $40 \mathrm{~mL} 0.5 \mathrm{~mol} \mathrm{~L}{ }^{-1} \mathrm{NH}_{2} \mathrm{OH} \cdot \mathrm{HCl}, \mathrm{pH} \sim 1.5$, shaken $16 \mathrm{~h}$ at room temperature, centrifuged as in Step 1 \\
\hline 3 & Oxidisable & $\begin{array}{l}\text { Digested with } 10 \mathrm{~mL} 8.8 \mathrm{~mol} \mathrm{~L}^{-1} \mathrm{H}_{2} \mathrm{O}_{2}, 1 \mathrm{~h} \text { at room temperature, } 1 \mathrm{~h} \text { at } 85^{\circ} \mathrm{C}, 10 \mathrm{~mL} 8.8 \mathrm{~mol} \mathrm{~L}^{-1} \mathrm{H}_{2} \mathrm{O}_{2} \text { added, } 1 \mathrm{~h} \mathrm{at} \\
85^{\circ} \mathrm{C} \text {, reduced volume, extracted with } 50 \mathrm{~mL} \text { of } 1 \mathrm{~mol} \mathrm{~L}^{-1} \mathrm{NH}_{4} \mathrm{COOCH}_{3} \text {, shaken } 16 \mathrm{~h} \text { at room temperature, centrifuged } \\
\text { as in Step } 1\end{array}$ \\
\hline 4 & Residual & $\begin{array}{l}7.5 \mathrm{~mL} 12 \mathrm{~mol} \mathrm{~L}-1 \mathrm{HCl}, 2.5 \mathrm{~mL} 16 \mathrm{~mol} \mathrm{~L}^{-1} \mathrm{HNO}_{3}, 16 \mathrm{~h} \text { at room temperature, } 2 \mathrm{~h} \text { gentle reflux, cool, filtered through } \\
\text { Whatman } 540\end{array}$ \\
\hline
\end{tabular}


and $3 \times 2 \mathrm{~mL}$ of Milli-Q $\mathrm{H}_{2} \mathrm{O}$ was used to quantitatively transfer the residue from the centrifuge tube with the majority of the moisture evaporated off at $60^{\circ} \mathrm{C}$ prior to digestion.

Independent aqua regia digestions were performed on separate samples of NIST 2711 for comparison to the sum of fractions 1-4 from the BCR extraction. The same method was used as for Step 4, residual, in the BCR procedure, although the sample was moistened with a few drops of Milli-Q water before aqua regia addition.

\subsection{Partial extraction}

A dilute acid partial extraction was also performed on the NIST 2711 reference material based on the partial extraction technique recommended by Snape et al. [14]. $20 \mathrm{~mL}$ of $1 \mathrm{~mol} \mathrm{~L}^{-1} \mathrm{HCl}$ was added to $1 \mathrm{~g}$ of sediment and shaken on an orbital shaker for $4 \mathrm{~h}$ at room temperature $\left(20^{\circ} \mathrm{C}\right)$, after which extracts were filtered through Whatman 540 filter paper and diluted to $100 \mathrm{~mL}$.

\subsection{Metal analysis}

Trace metal analyses were carried out using a magnetic sector ICP-MS (Finnigan Element 1, Bremen, Germany). This type of instrument has multiple resolution settings available enabling many spectrally interfered isotopes (typically of low mass) to be accurately measured interference free. Indium $\left(100 \mu \mathrm{g} \mathrm{L}^{-1}\right)$ was employed as an internal standard. External calibration was performed using standards prepared from $100 \mu \mathrm{g} \mathrm{mL}^{-1}$ multi element solutions (QCD Analysts-Environmental Science Solutions, Spring lake, USA). Calibration accuracy was verified by the regular analysis of external reference material NIST SRM 1640 "Trace Elements in Natural Water". Further details regarding the analytical methodology employed have been presented previously $[27,28]$.

\section{Results and discussion}

\subsection{Pseudo-total element analyses}

As was mentioned above, an aqua regia digest step has been incorporated into the optimised BCR sequential extraction procedure as a quality assurance measure. Results for aqua regia digests of NIST 2711 are shown in Table 2 with precisions less than $3 \%$ for all 12 elements analysed and quantitative recoveries (85-99\%), based on the NIST 2711 certified and non-certified total values, for ten out of 12 elements. Low recoveries for $\mathrm{Al}$ and $\mathrm{Cr}$ (39\% and 57\%, respectively) were not unexpected, as the aqua regia digest is not sufficient to achieve complete dissolution of siliceous and refractory materials, which is the basis for the NIST 2711 total values [26].

Also shown in Table 2 are recoveries based on non-certified NIST 2711 leachable concentrations obtained using US EPA Method 3050, a hot $\mathrm{HNO}_{3}-\mathrm{H}_{2} \mathrm{O}_{2}$ digest. The leachable concentrations were determined by a number of co-operating laboratories, with some variance in the methodology employed for the final step [26]. Recoveries based on leachable concentrations ranged from 97 to $147 \%$, with most recoveries greater than $100 \%$. Recoveries greater than $100 \%$ are to be expected, as the AS 4479.2 aqua regia digest is a stronger digest than the EPA Method 3050 hot $\mathrm{HNO}_{3}$ digest due to the length of time of the extraction and the relative strengths of the reagents employed.

\subsection{BCR element partitioning}

The sequential extraction results for NIST 2711 are shown in Table 3. The results are reported for a mean value \pm 1S.D. for three replicate determinations. The precisions obtained for the four individual fractions of the modified BCR sequential extraction procedure were less than $10 \%$ for all elements (except for $\mathrm{Fe}$ in the acid extractable fraction $(11 \%)$ and $\mathrm{Ni}(18 \%)$ in the

Table 2

Pseudo-total concentrations and recoveries for NIST 2711

\begin{tabular}{|c|c|c|c|c|c|}
\hline & Aqua regia $^{a}$ & NIST total ${ }^{\mathrm{b}}$ & NIST leachable ${ }^{c}$ & Total recovery ${ }^{\mathrm{d}}(\%)$ & Leachable recovery ${ }^{\mathrm{e}}(\%)$ \\
\hline $\mathrm{Cd}$ & $40.68 \pm 0.59$ & $41.70 \pm 0.25$ & $32-46(40)$ & 98 & 102 \\
\hline $\mathrm{Sb}$ & $18.5 \pm 0.4$ & $19.4 \pm 1.8$ & $(<10)$ & 95 & $>185$ \\
\hline $\mathrm{Pb}$ & $1067 \pm 31$ & $1162 \pm 31$ & $930-1500(1100)$ & 92 & 97 \\
\hline $\mathrm{Al}^{\mathrm{f}}$ & $2.53 \pm 0.76$ & $6.53 \pm 0.09$ & $1.2-2.3(1.8)$ & 39 & 141 \\
\hline $\mathrm{Cr}$ & $27 \pm 1$ & $(47)^{g}$ & $15-25(20)$ & 57 & 135 \\
\hline $\mathrm{Mn}$ & $544 \pm 6$ & $638 \pm 28$ & $400-620(490)$ & 85 & 111 \\
\hline $\mathrm{Fe}^{\mathrm{f}}$ & $2.45 \pm 0.44$ & $2.89 \pm 0.06$ & $1.7-2.6(2.2)$ & 85 & 111 \\
\hline $\mathrm{Co}$ & $9 \pm 0.1$ & $(10)^{\mathrm{g}}$ & $7-12(8.2)$ & 90 & 110 \\
\hline $\mathrm{Ni}$ & $17.7 \pm 0.2$ & $20.6 \pm 1.1$ & $14-20(16)$ & 86 & 111 \\
\hline $\mathrm{Cu}$ & $111 \pm 0.2$ & $114 \pm 2$ & $91-110(100)$ & 97 & 111 \\
\hline $\mathrm{Zn}$ & $334.0 \pm 2.6$ & $350.4 \pm 4.8$ & $290-340(310)$ & 95 & 108 \\
\hline As & $104 \pm 1$ & $105 \pm 8$ & $88-110(90)$ & 99 & 116 \\
\hline
\end{tabular}

a Average values ( \pm 1 S.D.) from three replicates as $\mu \mathrm{g} \mathrm{g}^{-1}$ dry weight unless otherwise stated.

b Certified NIST 2711 total values as $\mu \mathrm{gg}^{-1}$ dry weight unless otherwise stated [26].

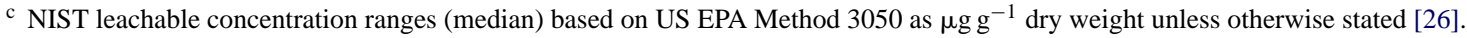

d Total recovery based on NIST 2711 certified and non-certified total values.

e Leachable recovery based on NIST 2711 leachable concentrations.

f Values for $\mathrm{Al}$ and $\mathrm{Fe}$ as wt\%.

g Non-certified NIST 2711 total values [26]. 
Table 3

BCR partitioning of NIST 2711

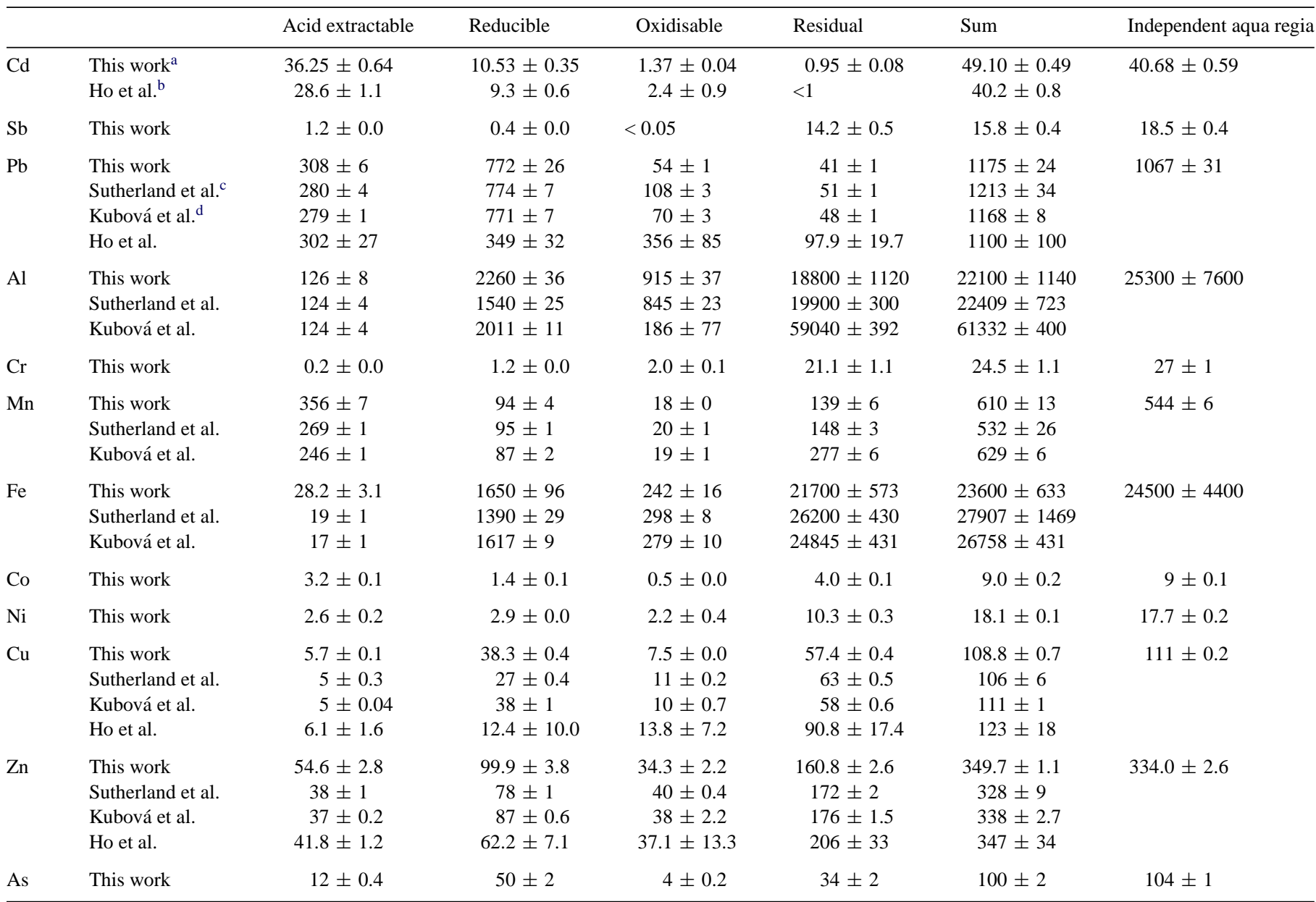

a Average values ( \pm 1S.D.) from five replicates as $\mu \mathrm{gg}^{-1}$ dry weight using optimised BCR procedure.

b Original BCR procedure [23].

c Optimised BCR procedure [24]. Original results for Mn were incorrectly published and revised results are shown [29].

d Optimised BCR procedure [25].

oxidisable fraction), with the majority of measured precisions for the 12 elements analysed less than $5 \%$. This excellent precision may be attributed to the fine grinding and good homogeneity of the reference material during the preparation of the soil, and careful handling and analysis during subsequent steps. The sum of the four fractions for the BCR procedure is in good agreement with the pseudo-total aqua regia element analyses, ranging from 86 to $121 \%$ for all elements; an excellent result considering the number of manipulations the BCR procedure requires.

The partitioning between phases of $\mathrm{Pb}, \mathrm{Al}, \mathrm{Mn}, \mathrm{Fe}, \mathrm{Cu}$ and $\mathrm{Zn}$ in NIST 2711 has previously been investigated using the optimised BCR procedure by Sutherland et al. and also by Kubová et al. [24,25], and prior to this Ho and Evans [23] have reported the fractionation of $\mathrm{Cd}, \mathrm{Cu}, \mathrm{Pb}$ and $\mathrm{Zn}$ using the original BCR procedure. As mentioned previously, the original BCR procedure was modified with the main difference being an increase in the concentration of the reducing agent used in Step 2 from $0.1 \mathrm{M}$ hydroxylammonium chloride to $0.5 \mathrm{M}$ hydroxylammonium chloride, and is now known as the optimised BCR. Whilst Sutherland et al. and Kubová et al. both used the optimised BCR procedure, Kubová et al. applied a $\mathrm{HF}-\mathrm{HNO}_{3}-\mathrm{HClO}_{4}$ residual digest in place of an aqua regia residual digest. Ho and Evans [23] also used a $\mathrm{HF}-\mathrm{HNO}_{3}-\mathrm{HClO}_{4}$ residual digest.

The partitioning pattern in the current work for $\mathrm{Pb}, \mathrm{Al}, \mathrm{Mn}$, $\mathrm{Fe}, \mathrm{Cu}$ and $\mathrm{Zn}$ was generally similar to previous results using the optimised BCR procedure, with the main discrepancies being for $\mathrm{Mn}, \mathrm{Fe}$ and $\mathrm{Zn}$ in the acid extractable fraction. Our results in all three cases are greater than the results of Sutherland et al. and Kubová et al., suggesting an over extraction of $\mathrm{Mn}, \mathrm{Fe}$ and $\mathrm{Zn}$ in Step 1 of our work. Discrepancies also exist between the previous work of Sutherland et al. and Kubová et al. for $\mathrm{Pb}$ and $\mathrm{Al}$ in the oxidisable fraction, and it is now apparent from our work that $\mathrm{Pb}$ was over-extracted by Sutherland et al. in Step 3, whilst Al was under-extracted by Kubová et al. in Step 3. It is also apparent that the higher residual $\mathrm{Al}$ and $\mathrm{Mn}$ concentrations reported by Kubová et al. are due to the use of $\mathrm{HF}-\mathrm{HNO}_{3}-\mathrm{HClO}_{4}$ for the residual digest, as opposed to an aqua regia residual digest as prescribed for the optimised BCR procedure.

Previous results for $\mathrm{Cd}, \mathrm{Cu}, \mathrm{Pb}$ and $\mathrm{Zn}$ partitioning in NIST 2711 by Ho and Evans [23] using the original BCR procedure 
have also been included in Table 3. Although Ho et al. scaled the mass of sample and volume of reagent down by $50 \%$, the first step was identical to the method used in this work. Apart from $\mathrm{Cd}$, there was little difference in the concentrations of metals extracted in Step 1, however, the effect of increasing the concentration of the reducing agent in Step 2 of the optimised BCR procedure can clearly be seen from the notably lower concentrations of $\mathrm{Pb}, \mathrm{Cu}$ and $\mathrm{Zn}$ extracted in Step 2 using the original $\mathrm{BCR}$ procedure. Comparison of the sum of the four fractions for the BCR procedure with the independent aqua regia digest suggests that our Cd value for Step 1 is higher than expected, but the Cd values for Steps 2-4 are consistent with the expectation of higher Step 2 values and lower Step 3 values for the optimised BCR procedure when compared with the original BCR procedure.

It is obvious from the results in Table 3 that a consequence of the lower reducing agent concentration in Step 2 of the original $\mathrm{BCR}$ procedure was an increase in $\mathrm{Cu}$ and $\mathrm{Zn}$ reporting to the residual fraction, and an increase in $\mathrm{Pb}$ reporting to the oxidisable and residual fractions. The effect of increasing the reducing agent concentration on the partitioning of metals clearly illustrates that the fractionation of metals using sequential extraction schemes, such as the BCR, is operationally defined in terms of the extraction procedure used to release the metals, rather than in terms of discrete geochemical phases.

\subsection{Dilute $\mathrm{HCl}$ partial extraction}

Dilute acid extractions provide a more sensitive means of assessing the environmentally labile and biologically available fraction of sediments due to the fact that concentrated acid extractions often do not differentiate between residual and labile fractions, and thus sediment contamination can be masked by high residual concentrations [3]. The partial extraction method used here was based on a method proposed by Snape et al. [14], which resulted from a kinetic study using $1 \mathrm{~mol} \mathrm{~L}^{-1} \mathrm{HCl}$. This study on marine sediments from the Casey Station area of East Antarctica found that a $4 \mathrm{~h} 1 \mathrm{~mol} \mathrm{~L}^{-1} \mathrm{HCl}$ extraction provided the best correlation with biological data, clearly identified sediments contaminated by run off from an abandoned waste disposal site, and provided better sensitivity for distinguishing between low and moderately contaminated sites $[14,17]$. The $4 \mathrm{~h}$ extraction time was also believed to provide better precision compared with a shorter extraction time, with variations in extraction time due to sample handling being less significant.

Partial extraction results for NIST 2711 are shown in Table 4 with precisions less than $4 \%$ for the 12 elements analysed. The partial extraction results have been compared to the NIST 2711 certified and non-certified total values, non-certified leachable concentrations, and the sum of the first three steps of the BCR procedure, which are considered to be the labile fractions. As to be expected, the partial extraction released less than $100 \%$ of the NIST 2711 total and leachable concentrations, and the low recoveries of $\mathrm{Al}, \mathrm{Fe}$ and $\mathrm{Cr}(<5 \%)$ indicates that the $4 \mathrm{~h} 1 \mathrm{~mol} \mathrm{~L}^{-1}$ $\mathrm{HCl}$ partial extraction does not attack residual minerals.

The $4 \mathrm{~h} 1 \mathrm{~mol} \mathrm{~L}^{-1} \mathrm{HCl}$ partial extraction has also been previously applied to two other reference materials, MESS-2, an
Table 4

Partial extraction results for NIST 2711

\begin{tabular}{lcccc}
\hline & Partial $^{\text {a }}$ & $\begin{array}{l}\text { Partial/NIST } \\
\text { total }(\%)\end{array}$ & $\begin{array}{l}\text { Partial/NIST } \\
\text { leachable }(\%)\end{array}$ & $\begin{array}{l}\text { Partial/ } \sum \text { BCR } \\
\text { Steps 1-3 }(\%)\end{array}$ \\
\hline $\mathrm{Cd}$ & $34.62 \pm 0.69$ & 81 & 85 & 70 \\
$\mathrm{Sb}$ & $1.66 \pm 0.04$ & 8.3 & $<16$ & 98 \\
$\mathrm{~Pb}$ & $855.0 \pm 6.3$ & 72 & 76 & 74 \\
$\mathrm{Al}$ & $2106 \pm 65$ & 3.2 & 11 & 63 \\
$\mathrm{Cr}$ & $1.40 \pm 0.05$ & 2.9 & 6.8 & 41 \\
$\mathrm{Mn}$ & $366.2 \pm 4.0$ & 56 & 73 & 76 \\
$\mathrm{Fe}$ & $1428 \pm 22$ & 4.8 & 6.4 & 73 \\
$\mathrm{Co}$ & $3.86 \pm 0.12$ & 38 & 46 & 75 \\
$\mathrm{Ni}$ & $4.26 \pm 0.06$ & 20 & 26 & 54 \\
$\mathrm{Cu}$ & $58.30 \pm 0.73$ & 50 & 57 & 111 \\
$\mathrm{Zn}$ & $109.0 \pm 1.1$ & 30 & 34 & 56 \\
$\mathrm{As}$ & $67.79 \pm 1.37$ & 63 & 74 & 101 \\
\hline
\end{tabular}

a Average partial extraction $\left(4 \mathrm{~h} 1 \mathrm{~mol} \mathrm{~L}^{-1} \mathrm{HCl}\right)$ values ( \pm 1S.D.) for five replicates as $\mu \mathrm{g} \mathrm{g}^{-1}$ dry weight of sediment.

uncontaminated estuarine sediment from the Beaufort Sea, and PACS-2, a contaminated sediment from Esquimalt Harbour $[14,30]$. Although the three reference materials differ in their sediment/soil types, the recoveries for the three reference materials, Table 5, are generally similar for most of the elements. All three reference materials had low $1 \mathrm{~mol} \mathrm{~L}^{-1} \mathrm{HCl}$ labile $\mathrm{Sb}$, $\mathrm{Cr}$ and $\mathrm{Fe}$, and the generally lower extraction efficiencies for MESS-2 is consistent with it being an uncontaminated sediment with the majority of metals associated with the residual phase, and hence less susceptible to attack by the $\mathrm{HCl}$ extraction.

Comparison of the partial extraction with the sum of the three labile steps of the BCR procedure provides a better indication of the effectiveness of a partial extraction, and it can be seen in Table 4 that whilst the partial extraction generally released less of each element than the BCR procedure, partial extraction recoveries based on the labile BCR fractions were generally significantly higher than recoveries based on the total and leachable concentrations. In fact, for 8 out the 12 elements the partial extraction recovery based on the labile BCR fractions was $>70 \%$.

Similarly Sutherland has also reported a strong correlation between a dilute $\mathrm{HCl}\left(1 \mathrm{~h} 0.5 \mathrm{~mol} \mathrm{~L}^{-1}\right)$ extraction and the labile fractions of the optimised BCR sequential extraction procedure, although in Sutherland's case the dilute $\mathrm{HCl}$ extraction appeared to be more aggressive than $\mathrm{BCR}$ sequential extraction procedure [12]. Despite the fact that dilute $\mathrm{HCl}$ is one of the more common partial extractants used [3,12-14,31], it is surprising that very little work has been undertaken to understand the relation-

Table 5

Partial extraction recoveries for three reference materials

\begin{tabular}{lcrrrrrrrrr}
\hline & $\mathrm{Cd}$ & $\mathrm{Sb}$ & $\mathrm{Pb}$ & $\mathrm{Cr}$ & $\mathrm{Mn}$ & $\mathrm{Fe}$ & $\mathrm{Ni}$ & $\mathrm{Cu}$ & $\mathrm{Zn}$ & $\mathrm{As}$ \\
\hline NIST 2711 $^{\mathrm{a}}$ & 81 & 8 & 72 & 3 & 56 & 5 & 20 & 50 & 30 & 63 \\
MESS-2 $^{\mathrm{b}}$ & 58 & $<1$ & 68 & 3 & 51 & 18 & 20 & 50 & 37 & 22 \\
PACS-2 $^{\mathrm{b}}$ & 99 & 3 & 87 & 14 & 13 & 18 & 24 & 68 & 81 & 42 \\
\hline
\end{tabular}

\footnotetext{
${ }^{\text {a }}$ Average recoveries $(\%)$ of partial extraction $\left(4 \mathrm{~h} 1 \mathrm{~mol} \mathrm{~L}^{-1} \mathrm{HCl}\right)$ for five replicates as $\mu \mathrm{g} \mathrm{g}^{-1}$ dry weight of sediment.

b Average recoveries (\%) of partial extraction $\left(4 \mathrm{~h} 1 \mathrm{~mol} \mathrm{~L}^{-1} \mathrm{HCl}\right)$ of MESS-2 and PACS-2 [30].
} 
ship between labile phases liberated by partial extractions and sequential extractions [12].

\section{Conclusion}

As a result of this work, and when combined with previous BCR extractions of NIST 2711, we can now be confident of the BCR partitioning of seven elements in NIST 2711, and BCR partitioning for a further five elements has been provided for the first time. Application of a pseudo-total aqua regia digest of NIST 2711 for quality assurance purposes has proved invaluable, with the comparison of the sum of the four BCR fractions with the pseudo-total aqua regia digest providing an additional assessment of the accuracy of the BCR partitioning.

Partial extraction $\left(4 \mathrm{~h} 1 \mathrm{~mol} \mathrm{~L}^{-1} \mathrm{HCl}\right)$ results for the same 12 elements analysed by the optimised BCR procedure exhibit a strong correlation with the sum of the three labile steps of the BCR procedure, but further work should be undertaken to understand the relationship between labile phases liberated by the $\mathrm{BCR}$ procedure and dilute $\mathrm{HCl}$ partial extractions.

The pseudo-total, sequential extraction and partial extraction values for NIST 2711 found in this work will prove useful for quality assurance purposes in future environmental research.

\section{References}

[1] ANZECC and ARMCANZ, Australian and New Zealand guidelines for fresh and marine water quality, Australian and New Zealand Environment and Conservation Council/Agriculture and Resource Management Council of Australia and New Zealand, Canberra, 2000.

[2] P. Quevauviller, TrAC-Trends Anal. Chem. 21 (2002) 774.

[3] H. Agemian, A.S.Y. Chau, Analyst 101 (1976) 761.

[4] A. Tessier, P.G.C. Campbell, M. Bisson, Anal. Chem. 51 (1979) 844.

[5] C. Kheboian, C.F. Bauer, Anal. Chem. 59 (1987) 1417.

[6] J.L. Gomez-Ariza, I. Giraldez, D. Sanchez-Rodas, E. Morales, Anal. Chim. Acta 399 (1999) 295.

[7] C. Whalley, A. Grant, Anal. Chim. Acta 291 (1994) 287.

[8] N. Belzile, P. Lecomte, A. Tessier, Environ. Sci. Technol. 23 (1989) 1015.
[9] A.M. Ure, P. Quevauviller, H. Muntau, B. Griepink, Int. J. Environ. Anal. Chem. 51 (1993) 135.

[10] G. Rauret, J.F. Lopez-Sanchez, A. Sahuquillo, R. Rubio, C. Davidson, A. Ure, P. Quevauviller, J. Environ. Monit. 1 (1999) 57.

[11] H. Agemian, A.S.Y. Chau, Arch. Environ. Contam. Toxicol. 6 (1977) 69.

[12] R.A. Sutherland, Appl. Geochem. 17 (2002) 353.

[13] B.A. Malo, Environ. Sci. Technol. 11 (1977) 277.

[14] I. Snape, R.C. Scouller, S.C. Stark, J. Stark, M.J. Riddle, D.B. Gore, Chemosphere 57 (2004) 491.

[15] A. Tessier, P.G.C. Campbell, Hydrobiologia 149 (1987) 43

[16] S.N. Luoma, G.W. Bryan, Estuar. Coast. Shelf. Sci. 15 (1982) 95.

[17] M.J. Riddle, R.C. Scouller, I. Snape, J.S. Stark, S.M. Kratzmann, S.C. Stark, C.K. King, S. Duquesne, D.B. Gore, From chemical monitoring to biological meaning: extraction techniques and biological interpretation of sediment chemistry data from the Casey Station region., in: A.H.L. Huiskes, W.W.C. Gieskes, J. Rozema, R.M.L. Schorno, S.M. van der Vies, W.J. Wolff (Eds.), Antarctic Biology in a Global Context, Backhuys Publishers, Leiden, 2003, pp. 285-289.

[18] G. Rauret, J.-F. Lopez-Sanchez, A. Sahuquillo, E. Barahona, M. Lachina, A.M. Ure, C.M. Davidson, A. Gomez, D. Luck, J. Bacon, M. Yli-Halla, H. Muntau, P. Quevauviller, J. Environ. Monit. 2 (2000) 228.

[19] J.F. Lopez-Sanchez, A. Sahuquillo, H.D. Fiedler, R. Rubio, G. Rauret, H. Muntau, P. Quevauviller, Analyst 123 (1998) 1675.

[20] M. Pueyo, G. Rauret, D. Luck, M. Yli-Halla, H. Muntau, P. Quevauviller, J.F. Lopez-Sanchez, J. Environ. Monit. 3 (2001) 243

[21] X. Li, B.J. Coles, M.H. Ramsey, I. Thornton, Analyst 120 (1995) 1415.

[22] G.E.M. Hall, G. Gauthier, J.-C. Pelchat, P. Pelchat, J.E. Vaive, J. Anal. Atom. Spect. 11 (1996) 787

[23] M.D. Ho, G.J. Evans, Anal. Commun. 34 (1997) 363.

[24] R.A. Sutherland, F.M.G. Tack, Anal. Chim. Acta 454 (2002) 249.

[25] J. Kubova, V. Stresko, M. Bujdos, P. Matus, J. Medved, Anal. Bioanal. Chem. 379 (2004) 108.

[26] National Institute of Science and Technology, Certificate of Analysis: Standard Reference Material 2711, Montana Soil (Moderately Elevated Trace Element Concentrations), Gaithersburg, MD, 2003.

[27] A.T. Townsend, Fresenius J. Anal. Chem. 364 (1999) 521.

[28] A.T. Townsend, J. Anal. At. Spectrom. 15 (2000) 307.

[29] R. Sutherland, Pers. Commun. (2005).

[30] R.C.L. Scouller, Geochemistry of marine sediments adjacent to Casey and Wilkes Stations, Antarctica; an empirical study of the distribution and potential impact of station-derived heavy-metal contaminants, MSc thesis, Department of Physical Geography, Macquarie University, Sydney, 2004.

[31] S. McCready, G.F. Birch, S.E. Taylor, Aust. J. Earth Sci. 50 (2003) 249. 